\title{
ANALISIS RISIKO BENCANA GEMPABUMI DI WILAYAH NUSA TENGGARA BARAT
}

\author{
Melki Adi Kurniawan ${ }^{1}$, Komang Ngurah Suarbawa ${ }^{1}$, Ardhianto Septiadhi ${ }^{2}$ \\ ${ }^{1}$ Jurusan Fisika, Fakultas Matematika dan Ilmu Pengetahuan Alam, \\ Universitas Udayana, Kampus Bukit Jimbaran, Badung, Bali Indonesia 80361. \\ 2. Badan Meteorologi Klimatologi dan Geofisika, Badung Bali \\ Email:ngurah_suarbawa@unud.ac.id
}

\begin{abstract}
Abstrak
Telah dilakukan penelitian identifikasi risiko bencana gempabumi di wilayah Nusa Tenggara Barat berdasarkan 3 faktor: faktor bahaya gempabumi yaitu percepatan getaran tanah maksimum (Peak Ground Acceleration = PGA), faktor kerentanan yaitu kepadatan penduduk perkecamatan, serta faktor ketahanan yaitu IPM (Indeks Pembangunan Manusia) perkecamatan di Provinsi Nusa Tenggara Barat. Perhitungan nilai PGA dilakukan menggunakan fungsi atenuasi Fukushima dan Tanaka dengan data parameter gempabumi dari tahun $1970-2014$ dengan kriteria magnitude $\geq 4.5 \mathrm{mB}$, kedalaman $\leq$ $60 \mathrm{~km}$ dan episenter pada rentang $7.5^{\circ}-12.5^{\circ} \mathrm{LS}$ dan $115^{\circ}-120^{\circ}$ BT sedangkan untuk perhitungan indeks risiko bencana gempabumi menggunakan metode AHP (Analitycal Hierarchy Process). Dari hasil perhitungan maka diperoleh daerah dengan tingkat risiko bencana gempabumi yang paling tinggi adalah Kabupaten Dompu bagian selatan, Kota Mataram, Kota Bima, Kab Bima bagian utara sedangkan yang paling rendah adalah Kab Sumbawa Barat dan Kabupaten Sumbawa bagian selatan.
\end{abstract}

Kata Kunci: PGA, kepadatan penduduk, IPM, bahaya, kerentanan, ketahanan, risiko bencana gempabumi.

\begin{abstract}
An investigation of risk identification earthquake disaster in Nusa Tenggara Barat by three factors: the danger factor of earthquakes is Peak Ground Acceleration(PGA), vulnerability factor is population density by district, as well as the capasity factors are HDI (Human Development Index) by district in the province of West Nusa Tenggara has be done. PGA value calculation was performed using the attenuation function Fukushima and Tanaka with earthquake parameter data from 1970 2014 with the criteria of magnitude $\geq 4.5 \mathrm{mB}$, depth $\leq 60 \mathrm{~km}$ and the epicenter in the range of $7.5^{\circ}$ $12^{\circ}$ and $115^{\circ}-120^{\circ}$ BT and for disaster risk index calculation earthquake using AHP (Analytical Hierarchy Process). From the calculation of the obtained regions with earthquake disaster risk levels are highest are southern Dompu, Mataram, Bima, northern Bima Regency while the lowest West Sumbawa regency and southern Sumbawa regency.
\end{abstract}

Keywords : $\quad$ PGA, population density, HDI, hazard, vulnerability, resilience, earthquake disaster risk.

\section{PENDAHULUAN}

Potensi bencana gempabumi yang mempengaruhi Pulau Nusa Tenggara Barat terdiri atas 2 bagian, yaitu zona subduksi 38
Indo-Australia di selatan Nusa Tenggara Barat dan patahan naik busur belakang (back arc thrust) di utara Nusa Tenggara Barat. Hal inilah yang menyebabkan frekuensi 
kejadian gempabumi di Nusa Tenggara Barat tinggi, Berdasarkan data BMKG terdapat beberapa gempabumi yang cukup besar dan menimbulkan bencana di kepulauan Sumbawa.

Setiap kejadian gempabumi menghasilkan goncangan tanah yang dapat diidentifikasikan melalui nilai percepatan getaran tanah pada suatu tempat. Semakin besar nilai percepatan getaran tanah yang terjadi disuatu tempat, semakin besar bahaya gempabumi yang mungkin terjadi. Besar kecilnya nilai percepatan getaran tanah tersebut menjadi salah satu faktor yang dapat menunjukkan tingkat risiko gempabumi.

Secara demografi, wilayah Nusa Tenggara Barat merupakan daerah yang mempunyai jumlah penduduk 4.773.795 jiwa. Kondisi tersebut merupakan salah satu faktor kerentanan berisiko tinggi yang sewaktu-waktu dapat menimbulkan kerugian besar jika terjadi bencana alam.

Semakin tinggi nilai IPM (Indeks Pembangunan Masyarakat) semakin tinggi kemampuan masyarakat untuk mempersiapkan diri dalam menghadapi bencana (Pusat Penelitian dan Pengembangan Sumber Daya Air, 2008), berdasarkan faktor bahaya, kerentanan dan kapasitas tersebut digunakan untuk menentukan tingkat risiko bencana gempabumi di wilayah Nusa Tenggara Barat.

\section{TINJAUAN PUSTAKA}

\subsection{Magnitude bodi (mB)}

Magnitude ini didefinisikan berdasarkan catatan amplitudoterbesardari gelombang $\mathrm{P}$ yang menjalar melalui bagian dalam bumi (Lay. T and Wallace.T.C. 1995). Secara umum perumusan magnitude body adalah:

$m B=\log (A / T)+Q(h, \Delta)$

dimana :

$\mathrm{A}=$ amplitudo maksimum

$\mathrm{T}=$ periode

$Q(h, \Delta)=$ koreksi kedalaman dan jarak

\subsection{Magnitude permukaan (Ms)}

Magnitude tipe ini didapatkan sebagai hasil pengukuran terhadap amplitude maksimum gelombang permukaan (surface waves). Perumusan magnitude surface sama denga magnitude body namun ampitudo yang digunakan adalah gelombang permukaan.

Dengan menggunakan data- data historis gempabumi, konversi Ms dan $\mathrm{mB}$ dapat dinyatakan dalam persamaan (Ibrahim, 2005):

$$
\begin{aligned}
& m B=2.5+0.63 \mathrm{Ms} \\
& \text { atau } \\
& M s=1.59 \mathrm{mB}-3.97 \quad(2.3) \\
& \text { 2.3. Percepatan Getaran Tanah } \\
& \text { Maksimum }
\end{aligned}
$$

\subsection{Percepatan Getaran Tanah}

Pada bangunan yang berdiri di atas tanah memerlukan kestabilan tanah agar bangunan tetap stabil. Percepatan gelombang gempa yang sampai di permukaan bumi disebut juga Peak Ground Acceleration (PGA) merupakan gangguan yang perlu dikaji untuk setiap kejadian gempabumi. Rumus empiris atenuasi yang digunakan dalam penelitian ini adalah rumus Fukushima dan Tanaka (1990) dengan bentuk rumusanya adalah:

$$
\begin{aligned}
& \log _{10}(P G A)=0.41 M s \\
& -\log _{10}\left(R+0.032 * 10^{0.41 M s}\right) \\
& -0.0034 R+1.30
\end{aligned}
$$

dimana: $\quad P G A=$ Percepatan Tanah, $\mathrm{R}=$ Jarak dari hiposenter ke titik pengukuran

\subsection{Kepadatan Penduduk}

Semakin padat penduduk di suatu daerah maka akan semakin rentan daerah tersebut terhadap bencana. Tingginya kepadatan penduduk mampu mengurangi tingkat pelayanan sosial wilayahnya misalnya kurangnya akses masyarakat untuk mendapatkan pelayanan sosial seperti kesehatan dan pendidikan sehingga hal ini mampu mengurangi kesiapan fisik dan pemahaman penduduk dalam menghadapi 
kejadian bencana. Kepadatan penduduk juga dapat mempersulit proses evakuasi.

\subsection{Indeks Pembangunan Manusia (IPM)}

IPM adalah suatu indeks sosial ekonomi yang bergantung pada 3 (tiga) faktor yaitu faktor kesehatan, pendidikan dan penghasilan. IPM memberikan suatu ukuran gabungan tiga komponen utama pembangunan manusia, yaitu Indeks panjang umur (longevity),Indeks pendidikan dan Indeks standar kehidupan. Semakin tinggi nilai IPM semakin tinggi kemampuan masyarakat untuk mempersiapkan diri dalam menghadapi bencana. (Pusat Penelitian dan Pengembangan Sumber Daya Air, 2008)

\section{METODE PENELITIAN}

\subsection{Perhitungan nilai dan kontur percepatan tanah}

Langkah-langkah yang dilakukan dalam menghitung nilai dan kontur percepatan getaran tanah maksimum adalah sebagai berikut:.

1. Memilih data katalog gempabumi di wilayah Nusa Tenggara Barat $\left(7.5^{\circ}\right.$ $12.5^{\circ} \mathrm{LS}$ dan $\left.115^{\circ}-120^{\circ} \mathrm{BT}\right)$ dengan magnitude $(\mathrm{M}) \geq 4.5 \mathrm{mB}$. kemudian dilakukan konversimagnitude body ke magnitude surface menggunakan rumus Gutenberg dan C.F. Richter seperti pada Persamaan 2.6.

2. Menghitung jarak episenter dari titik pengamatan dengan Persamaan 3.1.

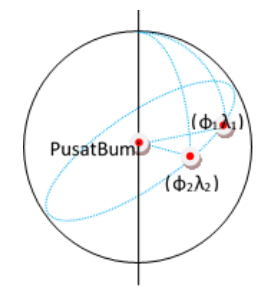

Gambar 3.1 Garis hubung pusat bumi dengan episenter dan titik pengamatan pada bidang bola

$$
\begin{aligned}
& \Delta=\operatorname{arc}\left(\sin \varphi_{1} \sin \varphi_{2}+\right. \\
& \left.\cos \varphi_{1} \cos \varphi_{2} \cos \left(\lambda_{1}-\lambda_{2}\right)\right) . r
\end{aligned}
$$

di mana :

$$
\begin{aligned}
& \Delta \quad=\text { jarak episenter } \\
& \lambda_{1}=\text { bujur posisi episenter } \\
& \varphi_{1}=\text { lintang posisi episenter, } \lambda_{2}= \\
& \text { bujur stasiun pengamat } \\
& \varphi_{2}=\text { lintang stasiun pengamat } r= \\
& \text { jari-jaribumi }=6.371 \mathrm{~km} .
\end{aligned}
$$

3. Menghitung jarak hiposenter ke titik pengamatan dengan rumus phytagoras seperti pada Persamaan 3.2.

$$
R=\sqrt{\Delta^{2}+h^{2}}
$$

dimana $\mathrm{h}=$ kedalaman sumber gempa (km).

4. Pembuatan peta PGA maksimum diawali dengan membuat grid dengan interval $0,15^{\circ}$ x $0,15^{\circ}$ pada rentang koordinat $7.5^{\circ}-9.5^{\circ}$ LS dan $115.5-$ 120 BT.

5. Menghitung nilai $P G A$ maksimum menggunakan rumus atenuasi Fukushima dan Tanaka (1990) sesuai persamaan (2.4).

6. Pembuatan kontur PGA maksimum.

\subsection{Analisis Tingkat Risiko Bencana Gempabumi}

Langkah-langkah yang dilakukan dalam menganalisis tingkat risiko bencana gempabumi adalah sebagai berikut:

1. Menentukan faktor dan indikator tingkat risiko bencana gempabumi. Identifikasi risiko bencana gempabumi di lokasi penelitian yaitu wilayah Nusa Tenggara Barat dilakukan berdasarkan pada 3 (tiga) faktor, yaitu faktor bahaya (hazard), dengan indikator PGA, faktor kerentanan (vulnerability) dengan indikator kepadatan penduduk, faktor ketahanan/kapasitas (capasity) dengan indikator rasio Indeks Pembangunan Manusia (IPM).

2. Menghitung standarisasi nilai indikator untuk menghasilkan nilai bakudengan Persamaan 3.3 dan Persamaan 3.4 (Davidson et al,1997). 
Untuk suatu indikator faktor bahaya dan kerantanan:

$$
X^{\prime}{ }_{i j}=\frac{X_{i j}-\left(\overline{X_{l}}-2 S_{i}\right)}{S_{i}}
$$

Untuk suatu indikator faktor ketahanan:

$$
X^{\prime}{ }_{i j}=\frac{-X_{i j}+\left(\overline{X_{l}}+2 S_{i}\right)}{S_{i}}
$$

dimana:

$X_{i j}^{\prime}=$ nilai yang sudah dibakukan untuk indikator i (hazard, vulnerability, capacity) di kecamatan $\mathrm{j}$

$X_{i j}=$ nilai yang belum dibakukan untuk indikator i di kecamatan $\mathrm{j}$

$\bar{X}_{l}=$ nilai rata-rata untuk indicator

$S_{i} \quad=$ standardeviasi

3. Pembobotan faktor dan indikator tingkat risiko bencana gempabumi.

Dalam penelitian ini nilai pembobotan merujuk pada penelitian yang sudah ada sebelumnya. Nilai pembobotan factor risiko bencana gempabumi (Firmansyah,2009), yaitu:

$I R B j=W h \cdot X H j+W v \cdot X v j+W c \cdot X c j=$ $0.350 X H j+0.340 X v j+0.310 X c j$

dimana :

$I R B=$ Indeks Risiko Bencana
$W h, W v, W c \quad=$ bobot untuk setiap faktor bencana

$X H, X v, X c=\quad$ nilai yang sudah dibakukan setiap faktor bencana

4. Menghitung tingkat risiko bencana gempabumi dari faktor-faktor yang mempengaruhinya (faktor bahaya, faktor kerentanan dan faktor ketahanan). Kemudian membaginya menjadi beberapa kelas menurut tingkatannya. Dalam penelitianinipenetapanbanyaknyakelasdib agimenjadi 5, yaitusangattinggi, tinggi, sedang, rendahdansangatrendah. Pembagian kelas menggunakan fitur data classification dalam Arc GIS 9.1 dengan metode natural breaks.

5. Membuat peta risiko bencana gempa bumi.

\section{IV.HASIL DAN PEMBAHASAN}

\subsection{Identifikasi Tingkat Bahaya Gempabumi}

Untuk mendapatkan gambaran tingkat bahaya bencana gempabumi di wilayah Nusa Tenggara Barat, maka dalam penelitian ini digunakan data historis gempabumi di wilayah Nusa Tenggara Barat dan sekitarnya tahun 1970 - 2014. Dengan memilih gempa dengan magnitudo $\geq 4,5 \mathrm{Mb}$ dan kedalaman dibawah $60 \mathrm{~km}$ didapat sebanyak 869 kejadian gempa. Peta sebaran gempabumi dapat dilihat pada Gambar 4.1.

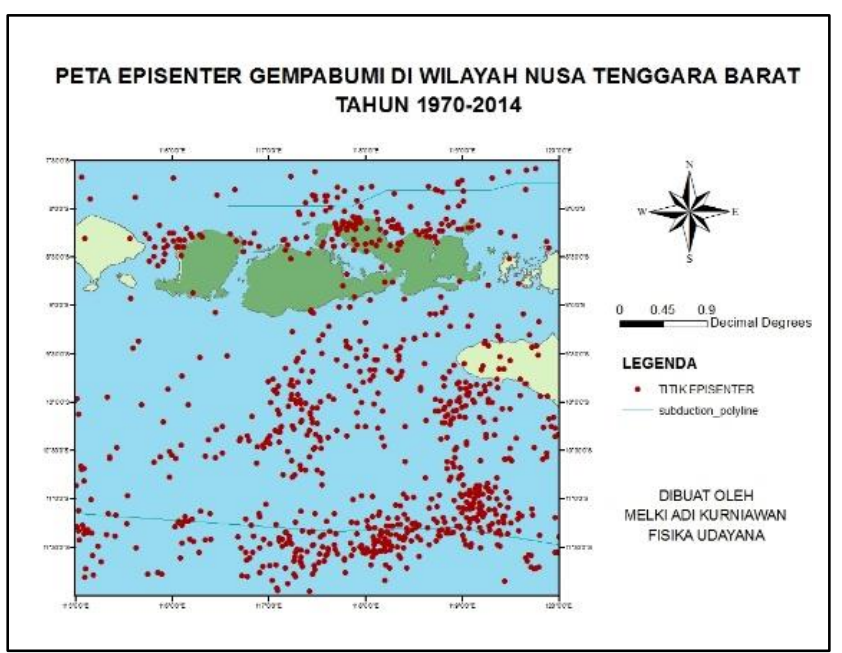

Gambar 4.1 Peta distribusi pusat gempabumi di Nusa Tenggara Barat dan sekitarnya (sumber : IRIS, 2015) 
Data gempabumi yang dipilih selanjutnya dihitung nilai PGA (Peak Ground Acceleration) maksimum di titik titik pengamatan. Contoh perhitungan di satu titik perhitungan dengan 1 data gempabumi. Contoh perhitunganya digunakan kejadian gempabumi pada 9Januari 1970, episenter: 9.27 LS, 117.25BT, kedalaman (h): $58 \mathrm{~km}$, magnitudo: $5.7 \mathrm{mB}$ dan koordinat titik perhitungan : $9.2 \mathrm{LS}, \quad \begin{array}{lll}119.4 & \mathrm{BT}\end{array}$ mendapatkan nilai $P G A=2.38$ gal. Perhitungan ini dilanjutkan untuk seluruh data hingga tahun 2014 sehingga didapat nilai $P G A$ maksimum untuk titik pengamatan -9.2 LS, 119,4 BT adalah 40.42 gal, dengan cara yang sama dilakukan untuk titik - titik pengamatan lainnya.

Nilai $P G A$ maksimum yang diperoleh di tiap titik dibuat peta kontur $P G A$ maksimum untuk wilayah Nusa Tenggara Barat menggunakan Software ArcGIS 9.1 dengan interpolasi krigging. Hasilnya dapat dilihat pada Gambar 4.2.

Tabel 4.1 Perhitungan PGA Maksimum pada titik 9.2 LS 119.4 BT

\begin{tabular}{|c|c|c|c|c|c|c|c|}
\hline \multicolumn{5}{|c|}{ PARAMETER GEMPABUMI } & \multirow{2}{*}{$\mathbf{R}(\mathbf{k m})$} & \multirow{2}{*}{$\log P G A$} & \multirow{2}{*}{$P G A$ (gal) } \\
\hline TANGGAL (GMT) & LINTANG $\left({ }^{\circ}\right)$ & BUJUR $\left({ }^{\circ}\right)$ & $\mathbf{H}(\mathrm{km})$ & Ms & & & \\
\hline 9-Jan-70 & -9.27 & 117.25 & 58 & 5.09 & 243.11 & 0.38 & 2.38 \\
\hline 22-Jan-70 & -7.88 & 115.62 & 35 & 3.66 & 119.13 & 0.32 & 2.07 \\
\hline 20-Apr-70 & -9.91 & 119.19 & 40 & 4.78 & 420.59 & -0.80 & 0.16 \\
\hline 22-Apr-70 & -11.39 & 120 & 33 & 4.93 & 564.31 & -1.35 & 0.04 \\
\hline$\ldots$ & $\ldots$ & $\ldots$ & $\ldots$ & $\ldots$ & $\ldots$ & $\ldots$ & $\ldots$ \\
\hline 19-Dec-73 & -9.52 & 119.39 & 42.10 & 5.57 & 33.95 & 1.61 & 40.42 \\
\hline$\ldots$ & $\ldots$ & $\ldots$ & $\ldots$ & $\ldots$ & $\ldots$ & $\ldots$ & $\ldots$ \\
\hline 5-Dec-14 & -9.3 & 118.75 & 10 & 3.66 & 359.40 & -0.98 & 0.11 \\
\hline 12-Dec-14 & -8.23 & 118.6 & 17 & 3.50 & 348.81 & -0.99 & 0.10 \\
\hline 27-Dec-14 & -8.94 & 118.05 & 12 & 3.66 & 280.12 & -0.60 & 0.25 \\
\hline
\end{tabular}

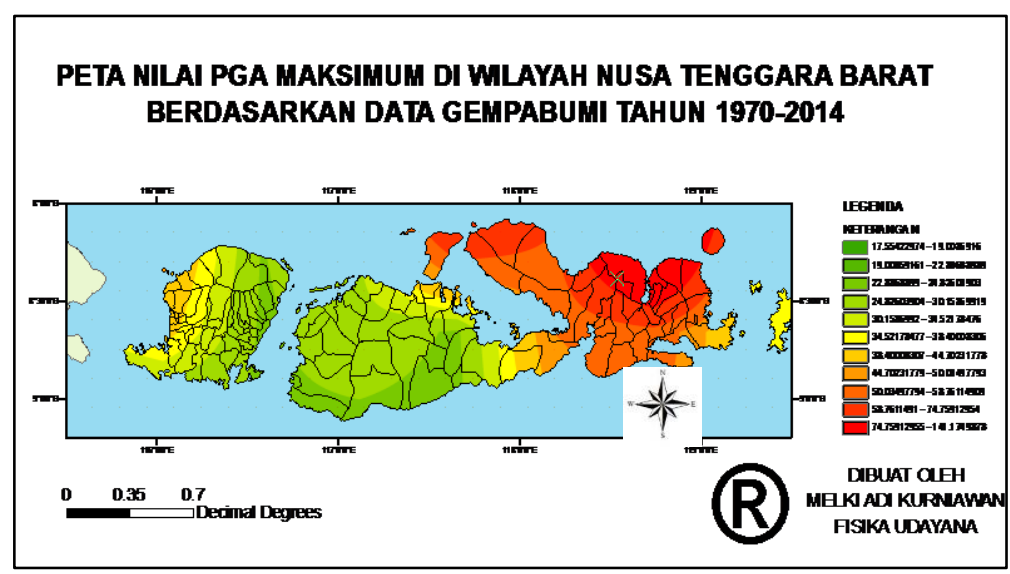

Gambar 4.2 Peta Peak Ground Acceleration Wilayah Nusa Tenggara Barat

Dari peta kontur diatas dapat ditentukan nilai PGA maksimum perkecamatan. Nilai PGAperkecamatan selanjutnya dihitung nilai bakunya, nilai baku tersebut kemudian diklasifikasikan menjadi 5 kelas untuk mengetahui tingkat bahaya gempabumi di wilayah Nusa Tenggara Barat. Perhitungan nilai baku.Perhitungan Nilai Baku PGA untuk titik $(-9.2,119.4)$ mendapatkan nilai 2.01. 
Nilai baku PGA per kecamatan diklasifikasikan menjadi 5 kelas dan dipetakan berdasarkan kategori tingkat bahayanya. Pada peta bahaya bencana

gempabumi (gambar 4.3) dapat diketahui wilayah yang memiliki tingkat bahaya sangat tinggi berada di wilayah Kabupaten Dompu dan Kota Bima.

\section{PETA TINGKAT BAHAYA GEMPABUMI DI NUSA TENGGARA BARAT}

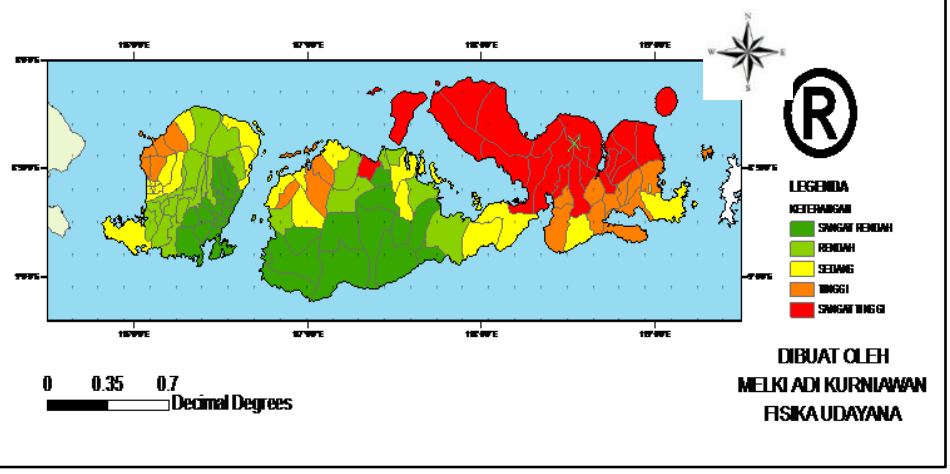

Gambar 4.3 Peta tingkat bahaya bencana gempabumi wilayah Nusa Tenggara Barat

\subsection{Identifikasi tingkat kerentanandan ketahanan bencana gempabumi}

Untuk mengidentifikasi tingkat kerentanan digunakan data kepadatan penduduk perkecamatan, sedangkan umtuk identifikasi tingkat ketahanan menghadapi bencana gempabumi digunakan data IPM. Data kepadatan penduduk dan IPM yang didapat selanjutnya dihitung nilai bakunya untuk menentukan indeks kerentanan dan ketahanan wilayah tersebut apabila terjadi kejadian gempabumi. Kemudian ditentukan kelas tingkatan kerentanan dan ketahanan di setiap kecamatan untuk dapat diketahui daerah mana saja yang memiliki tingkat kerentanan dan ketahanan sangat rendah sampai sangat tinggi.
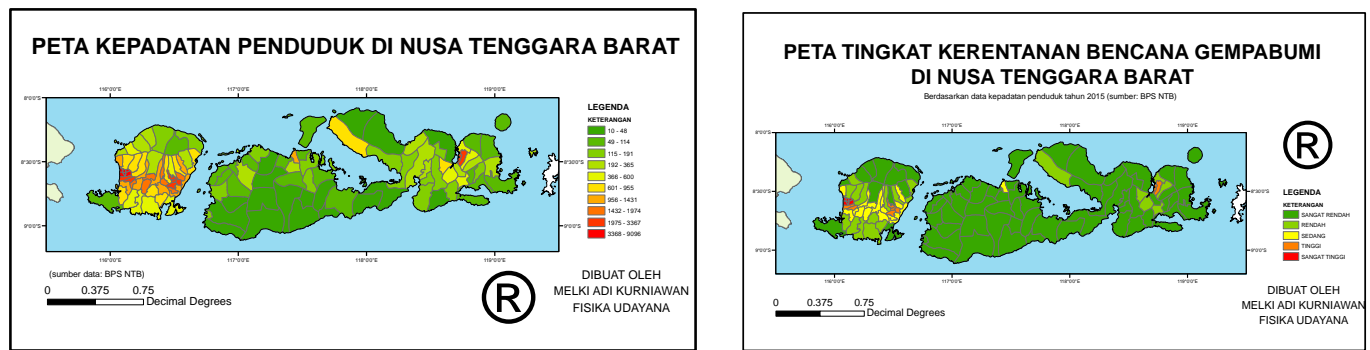

Gambar 4.4 Peta kepadatan penduduk dan tingkat kerentanan perkecamatan di Nusa Tenggara Barat

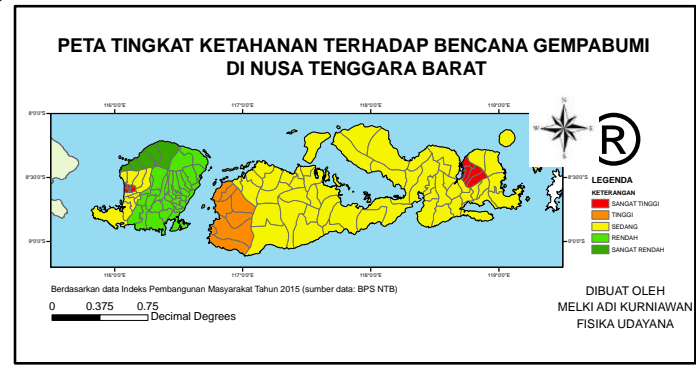

Gambar 4.5 Peta tingkat ketahanan menghadapi bencana gempabumi wilayah Nusa Tenggara Barat 


\subsection{AnalisisTingkat Risiko Bencana Gempabumi di Wilayah Nusa Tenggara Barat}

Tingkat risiko bencana gempabumi dihitung berdasarkan nilai baku dari PGA, kepadatan penduduk dan IPM dengan persamaan 3.5. Hasil perhitungan IRB untuk Kota Mataram dapat dilihat pada tabel 4.2. Dengan cara yang sama dilakukan untuk kabupaten dan kota yang lain kemudian disajikan dalam bentuk peta dapat dilihat pada gambar 4.6.

Wilayah dengan tingkat risiko bencana gempabumi sangat tinggi terdapat di Kabupaten Dompu, Kabupaten Bima, Kota Bima dan Kota Mataram.Wilayah dengan dengan tingkat risiko bencana gempabumi yang sangat rendah berada di Sumbawa Barat bagian selatan dan Sumbawa bagian selatan.

Tabel 4.2 Tabel hasil perhitungan Indeks Risiko Bencana di salah satu kota di wilayah penelitian

\begin{tabular}{|l|l|r|r|r|r|r|r|r|r|}
\hline \multicolumn{1}{|c|}{ KOTA } & KECAMATAN & $\begin{array}{r}\text { KEPADATAN } \\
\text { PENDUDUK }\end{array}$ & \multicolumn{1}{|c|}{ IPM } & \multicolumn{1}{c|}{ PGA } & $\begin{array}{r}\text { NILAI BAKU } \\
\text { PENDUDUK }\end{array}$ & $\begin{array}{r}\text { NILAI BAKU } \\
\text { IPM }\end{array}$ & $\begin{array}{c}\text { NILAI } \\
\text { BAKU PGA }\end{array}$ & IRB & TINGKAT \\
\hline Kota Mataram & Ampenan & 9096.00 & 75.93 & 47.79 & 6.92 & 1.45 & 2.04 & 3.52 & Sangat Tinggi \\
\hline Kota Mataram & Cakranegara & 6879.00 & 75.93 & 43.62 & 5.58 & 1.45 & 1.85 & 2.99 & Sangat Tinggi \\
\hline Kota Mataram & mataram & 7570.00 & 75.93 & 42.31 & 5.99 & 1.45 & 1.79 & 3.11 & Sangat Tinggi \\
\hline Kota Mataram & Sandubaya & 6785.00 & 75.93 & 42.09 & 5.52 & 1.45 & 1.78 & 2.95 & Sangat Tinggi \\
\hline Kota Mataram & Sekarbela & 6057.00 & 75.93 & 44.46 & 5.08 & 1.45 & 1.89 & 2.84 & Sangat Tinggi \\
\hline Kota Mataram & Selaparang & 6919.00 & 75.93 & 42.06 & 5.60 & 1.45 & 1.78 & 2.98 & Sangat Tinggi \\
\hline
\end{tabular}

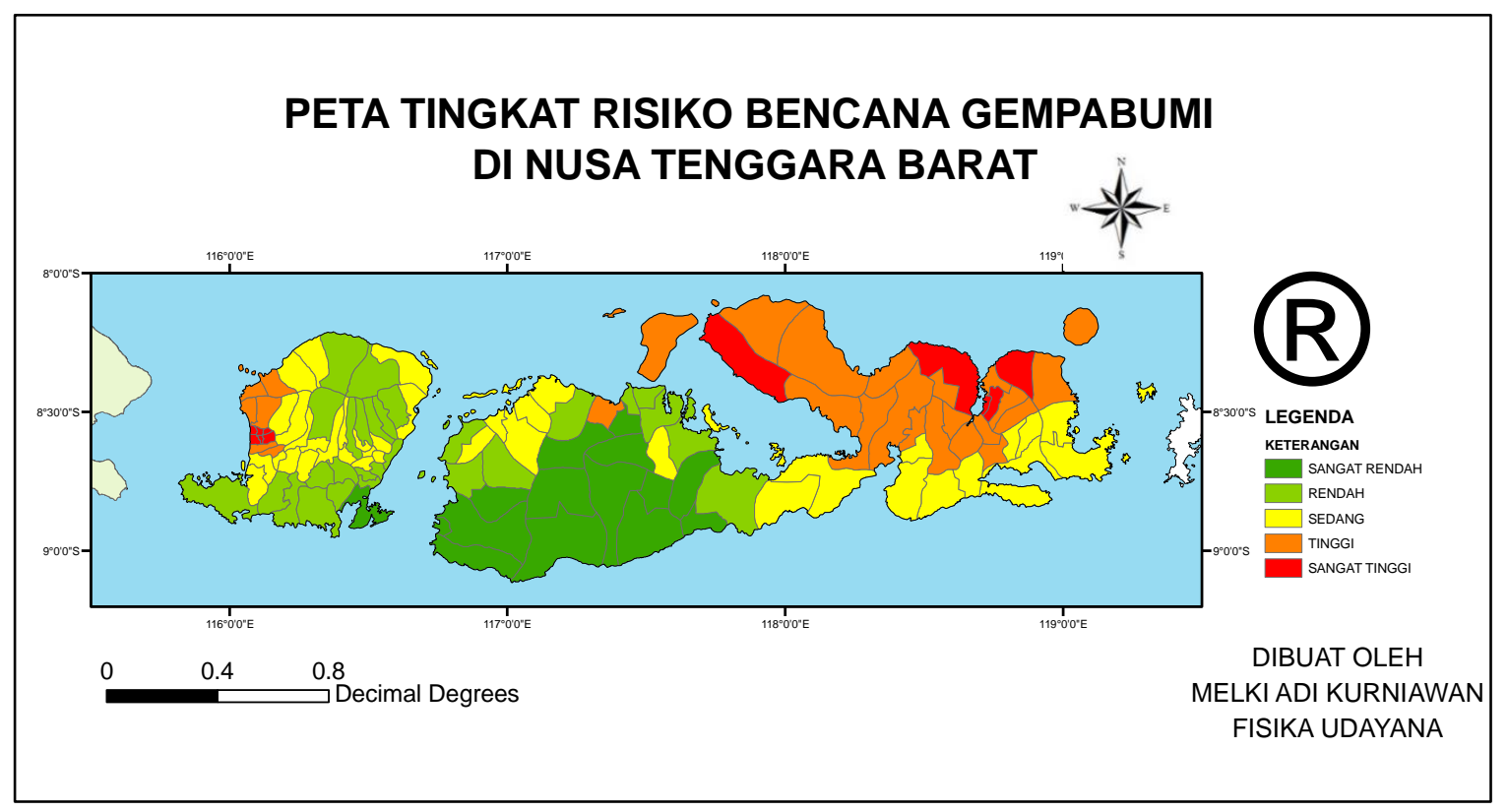

Gambar 4.6 Peta tingkat risiko bencana gempabumi wilayah Nusa Tenggara Barat

\section{KESIMPULAN DAN SARAN}

\subsection{Kesimpulan}

Dari uraian diatas dapat disimpulkan daerah dengan tingkat risiko bencana gempabumi yang paling tinggi adalah Kabupaten Dompu bagian selatan, Kota Mataram, Kota Bima, Kab Bima bagian utara sedangkan yang paling rendah adalah Kab Sumbawa Baratdan Sumbawa bagian selatan.

\subsection{Saran}

Penelitian ini dapat dilanutkan dengan penambahan faktor - faktor lain yang 
mempengaruhi tingkat risiko bencana gempabumi di wilayah Nusa Tenggara Barat

Hasil kalsinasi selanjutnya digerus di dalam mortar dengan pastel selama 4 jam sehingga diperoleh campuran yang sangat halus. Sampel selanjutnya dicetak menjadi pelet berdiameter $1,5 \mathrm{~cm}$ dengan menggunakan press hidrolik $\sim 400 \mathrm{kPa}$. Pelet disintering di dalam tungku pada suhu $910^{\circ} \mathrm{C}$ selama 30 jam di dalam atmosfir udara di dalam tungku. Pendinginan dilakukan sesuai dengan pendinginan didalam tungku.

\section{DAFTAR PUSTAKA}

Afnimar, 2009, Seismologi, Institut Teknologi Bandung, Bandung, 95 103

Desmonda, N.I dan Pamungkas Adjie, 2014, Penentuan Zona Kerentanan Bencana Gempabumi Tektonik di Kabupaten Malang Wilayah Selatan, Institut Teknologi Sepuluh November, Surabaya,

Darsono,Rudi, 2014, Analisis Tingkat Resiko Gempabumi Wilayah Bali, Universitas Udayana, Denpasar

Pemetaan Tingkat Risiko Bencana Alam Gempa Berbasis Sistem Informasi Geografis untuk Kepulauan Indonesia, Vol. 1, Pusat Penelitian dan Pengembangan Sumber Daya Air, 2008, 109 - 179
Edwiza, Daz dan S. Novita, 2008, Pemetaan Percepatan Tanah Maksimum Dan Intensitas Seismik Kota Padang Panjang Menggunakan Metode Kanai, Universitas Andalas, Padang, 2

Firmansyah, Oki dan Erwin T., 2009, Identifikasi Tingkat Risiko Bencana Gempa Bumi dan Tsunami Serta Arahan Tindakan Mitigasi Bencana Di Wilayah Pesisir Kabupaten Sukabumi, Universitas Pasundan, Bandung

Firmansyah, 2011, Identifikasi Tingkat Resiko bencana Gunung Api Gamalama di Kota Ternate, Unversitas Pasundan, Bandung, 2-5

Gempabumi, Badan Meteorologi Klimatologi dan Geofisika, http://www.bmkg.go.id/BMKG_Pusat/ Geofisika/Gempabumi.bmkg, Diakses pada tanggal 25 Agustus 2015

Ibrahim, Gunawan, 2005, Pengetahuan Seismologi, BMKG

https://ds.iris.edu/SeismiQuery/sqeventsmag.htm, diakses pada 20 agustus 2015

Peraturan Badan nasional Penanggulangan Bencana No 2 tahun 2012 tentang Pedoman Umum Pengkajian Bencana Indonesia

Mueck,Matthias, 2013,Peta-Peta Bahaya Tsunami Untuk Lombok, Publikasi bersama oleh GIZ dan DLR, Lombok 4-7. 